\title{
Technology Facilitation Assessment for Malaysia Halal Quality Assurance for Food and Beverages, Consumer Goods, Logistics, and Cosmetics Industry
}

\author{
Zuhra Junaida Mohamad Husny Hamid ${ }^{1}$, Mohd Iskandar Illyas ${ }^{2}$ and Farahwahida Mohd Yusof 3 \\ ${ }^{1}$ Center for Innovative Planning and Development (CIPD), Universiti Teknologi Malaysia, 81310 \\ Johor Bahru, Malaysia. \\ ${ }^{2}$ Azman Hashim Business School, Universiti Teknologi Malaysia, 81310 Johor Bahru, Malaysia. \\ ${ }^{3}$ Centre of Research for Fiqh Science and Technology (CFiRST), Universiti Teknologi Malaysia, \\ 31310 Johor Bahru, Malaysia.
}

Correspondence should be addressed to Zuhra J. M. Husny: z.junaida@utm.my

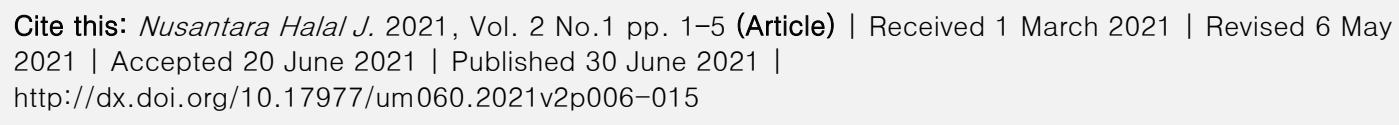

\begin{abstract}
This study aimed to identify the appropriate characteristics of assistive technology to facilitate the quality control process in halal industry segments, namely, food and beverages, consumer goods, logistics, and cosmetics. For this purpose, four separate research projects were conducted to cover these four different industry segments. This paper combined the findings and provided a compilation of all the results. Questionnaire surveys were distributed during the $13^{\text {th }}$ Malaysian International Halal Showcase (MIHAS 2016) as the pilot study. Main data collection was done on the industry in Johor in the southern part of Malaysia. The seven elements of technology characteristics selected for this study are speed, convenience, integration, autoreport, customizable, cost, and data accessibility. Findings of this study show that each industry segments have different technology characteristics preference. Nevertheless, the majority of respondents agreed that technological assistance in halal quality control is vital in helping companies to ensure the halal integrity of their products and services.
\end{abstract}

Keywords: Facilitation assessment, assistive technology, facilitate quality, halal industry.

\section{Introduction}

Halal certification by the Department of Islamic Development Malaysian (JAKIM) is the highest Halal logo recognized worldwide. Malaysia is the only country that has its halal authority under the government department. Malaysia has the most comprehensive halal standards, guidelines, and manuals to date compare to other nations in the world. Malaysia is the first country in the 
world to introduce Halal status and Halal logo in 1971 and the first halal standard (MS1500) in 2004 [1]. This portrays the commitment of Malaysia in gearing to be the world leader in the halal industry.

Currently, Malaysia has gazette 13 Halal standards addressing seven industry categories. On top of that, there are other related documents such as halal manuals, guidelines, and procedures. A halal product or service should portray the highest quality of product and services. Sungkar et Al. stated that halal integrity means that the halal product is being sourced, produced, stored, and distributed in the manner coherent with the Islamic values, where these are in line with the modern and universal values such as high quality and safety, hygienically produced with respect for animal welfare and traded [2]. This also means to achieve the halal status; a product and service not only need to comply with shariah law but also pass the other quality accreditations such as MESTI, GMP, HACCP, ISO, and other related quality assurance accreditations. Although all these quality documents are very important in helping to uphold the integrity and quality of halal products and services, to read thru, understand, identify, and compile the related clause and develop the appropriate checklist are very tedious and exhaustive. A finding from a preliminary study shows that complying with JAKIM halal certification is perceived as costly, tedious, and time-consuming.

This study focused on technology as part of the solution in overcoming the problems mentioned. The importance of information technology (IT) has increase and rapidly becoming the most important factor in productivity and cost reduction [3-6]. Weston claimed that IT could act as a feedback mechanism to users who are keen on measuring productivity. This may refer to acquire rapid and accurate information and improve communication links. Technology should also be friendly enough for users to feel at ease in performing their tasks. This posits that to change the industry's unhealthy perception of the process of acquiring halal certification, and at the same time promote the industry to adopt halal, and information technology can be proposed as the possible solution to the current problems. This study was intended to achieve two objectives; 1) to identify the technology requirements that the industry needs in helping them to pursue or carry the tasks in managing halal quality control, 2) to evaluate the perceived significant technology requirements for industry to conform the halal quality standard.

\section{Literature Review}

An extensive literature review has been done to really understand the current situation of halal implementation in Malaysia. Numerous areas of subjects in regards to halal control and certification have been reviewed, and among them are the concept of halalan toyibban, haram critical control point, halal application process, current halal certification technology and technological characteristics of what is perceived as useful and ease by technology user.

\section{Halalan Toyibban and Haram Critical Control Point (HrCCP)}

Halal has been widely accepted as one of the quality indicators for high-quality products and services. Currently, products and services that bear the status of halal, especially from halal JAKIM, will gain a higher market value. JAKIM halal logo has been recognized as the most preferred halal brand as it represents the Shariah law as well as other quality standards. Halal should not only be viewed from the perspective of the product is being produced but also on handling of the product throughout all processes of it reaching the consumers. This complete 
supply chain cycle is referred to as "from farm to fork." This concept should ensure that there would not be any cross-contamination between halal product and non-halal substance, which will result in the halal product turn to be non-halal (haram) or subhah. There are seven categories of halal certification schemes in Malaysia: food and beverages, cosmetics, pharmaceuticals, consumer goods, logistics, food premise, and slaughterhouse.

On top of complying with standards based on the seven schemes to acquire halal status, a company must identify Haram Critical Control Point (HrCCP) in their working process. HrCCP is a critical point in the production of goods process that can cause the finished product to be haram or subhah and unsafe to be consumed by humans. HrCCP plays a vital role in the halal assurance management system which, is the main element of enquiring Halal status. HrCCP is closely related to the audit process where the halal checklist is prepared, basically to ensure the HrCCPs are monitor systematically. Moreover, the proper control and monitoring of HrCCPs should be supported with supporting documents and evidence.

\section{Halal Application Process}

Application of halal certification from JAKIM will involve three main phases, namely application process, audit process, and approval process, as shown in Figure 1. These stages involve both parties, companies as applicants and JAKIM as the certification body [7].

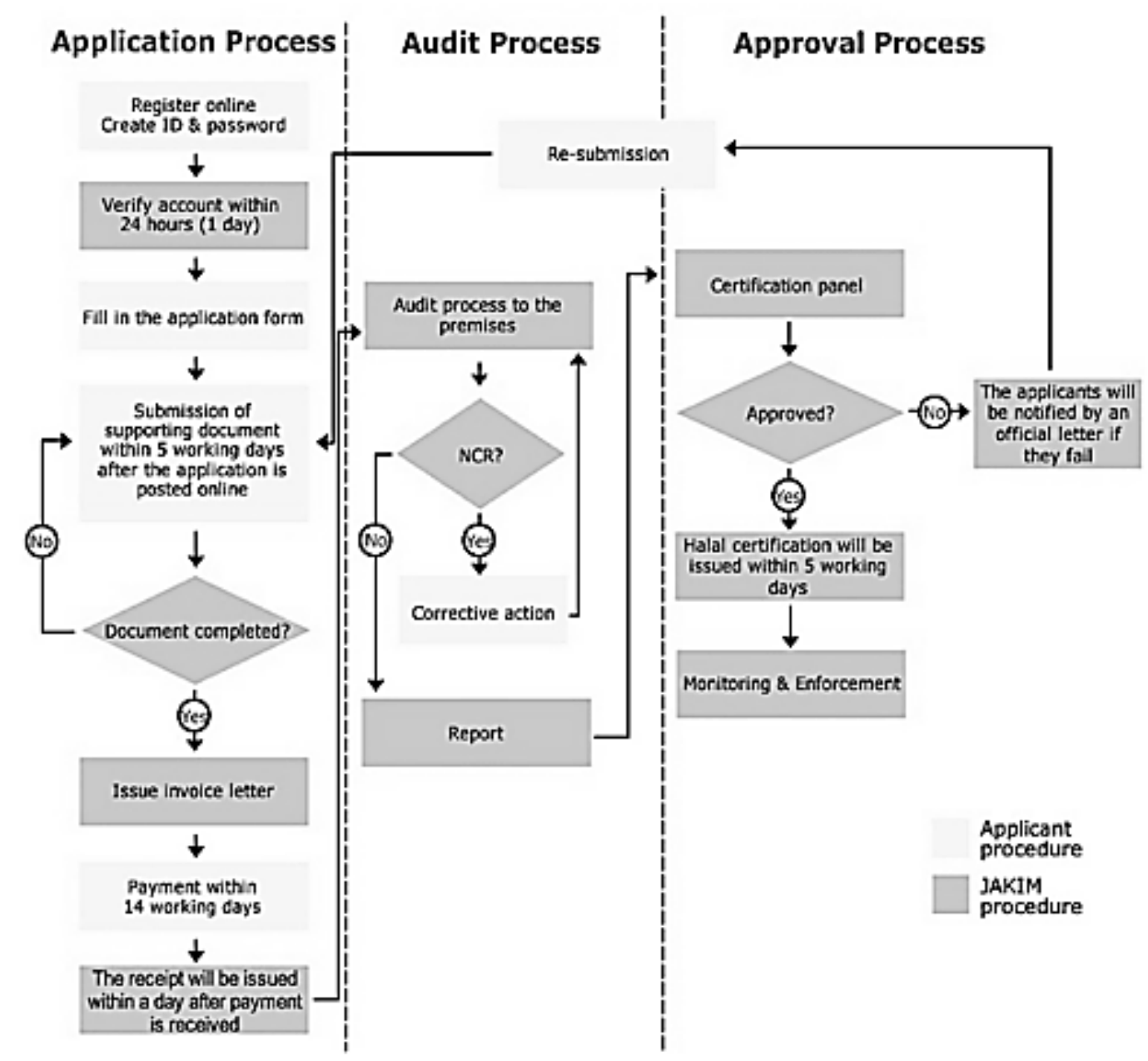

Figure 1. Process Flow of JAKIM Halal Certification 
Among these processes, the most critical and complex is the audit process. The audit process is divided into two parts: document audit and site audit. Document audit will be done after the applicant submitted the online application form, followed by submitting all relevant supporting documents within five working days. Failing to do this will cause the application not to be processed and the application will be reset, and a new application form needs to be resubmitted. If all documents are completed, JAKIM auditors will conduct a site audit at the applicant's premises. According to JAKIM auditor, most applications failed due to the unreadiness of the company in terms of providing supporting documents as evidence that they have fulfilled the halal standard requirement.

Furthermore, the company also needs to prove that they have a halal monitoring system incorporated in their business process [8]. Understanding the requirement, standards, and procedures of halal certification is very challenging and overwhelming to some companies, especially first-time applicants. This situation has impeded the motivation of companies to pursue halal certification, particularly by small-medium enterprises.

\section{Halal Certification Technology}

Technology is s an instrument that was created to facilitate processes or daily affairs. The term "technology" is not easy to define due to time and the different levels of understanding among researchers and philosophers. However, Oxford Dictionaries, technology is defined as the application of scientific knowledge for practical purposes, especially in industry. In the perspective of business, BusinessDictonary.com defined technology as the purposeful application of information in the design, production, and utilization of goods and services and in the organization of human activities. Frank et al. stated in their study that information technology has not only to play a great role in total quality management (TQM) but also facilitate the process in the main act as an enabler [9]. The study by Brah et al. has conformed the same for TQM in logistics companies [10]. Therefore, there is no doubt that technology is crucial for a total quality management system to work effectively and efficiently. According to Husny et al., there are eight technologies have been developed specifically to support halal certification activities [11], as shown in Table 1.

Table 1. Halal Certification Technology

\begin{tabular}{llll}
\hline No & Type & Category & Introducer \\
\hline 1 & My e-Halal & Web-Based Technology & JAKIM \\
2 & JAKIM My SMS 15888 & Mobile Phone Technology & JAKIM \\
3 & HaFYS Technology & Machine Technology & Halalysis Sdn. Bhd. \\
4 & MyMobilHalal 2.0 & Mobile Phone Technology & Syahrul Junanini and Johari Abdullah \\
5 & HDC Halal Widget & Web-Based Technology & HDC \\
6 & HDC i-Kiosk & Machine Technology & HDC \\
7 & HDC Nokia Apps & Mobile Phone Technology & HDC \\
8 & HDC iPhone & Mobile Phone Technology & HDC \\
\hline
\end{tabular}

The technology listed was developed to provide information on the halal status, whether it is halal certified or not. To date, there is no research and development focus on assisting the industry to ensure their product and services comply with the halal requirement. Surprisingly, this is the most crucial part of getting to be halal certified that more study to be conducted. 


\section{Formation of Research Model}

Based on the literature reviews and preliminary study, a conceptual framework has been developed based on seven characteristics of technology assistance needed to facilitate industries in monitoring their halal quality control activities. These characteristics are also looked from the perspective of its perceived usefulness and perceived ease of use of Technology Acceptance Model (TAM) [12-14]. Characteristics identified from literatures were then used in the preliminary study to validate the characteristics, which then form the research constructs. During the preliminary study four experts in halal industry and information technology has been interviewed. The characteristics chosen for this study are: 1) speed, 2) convenient, 3) integrated, 4) auto-report, 5) customizable, 6) cost-effective, and 7) transparency of data. This is important to achieve halal certification from JAKIM. Figure 2 shows the conceptual framework for this research.

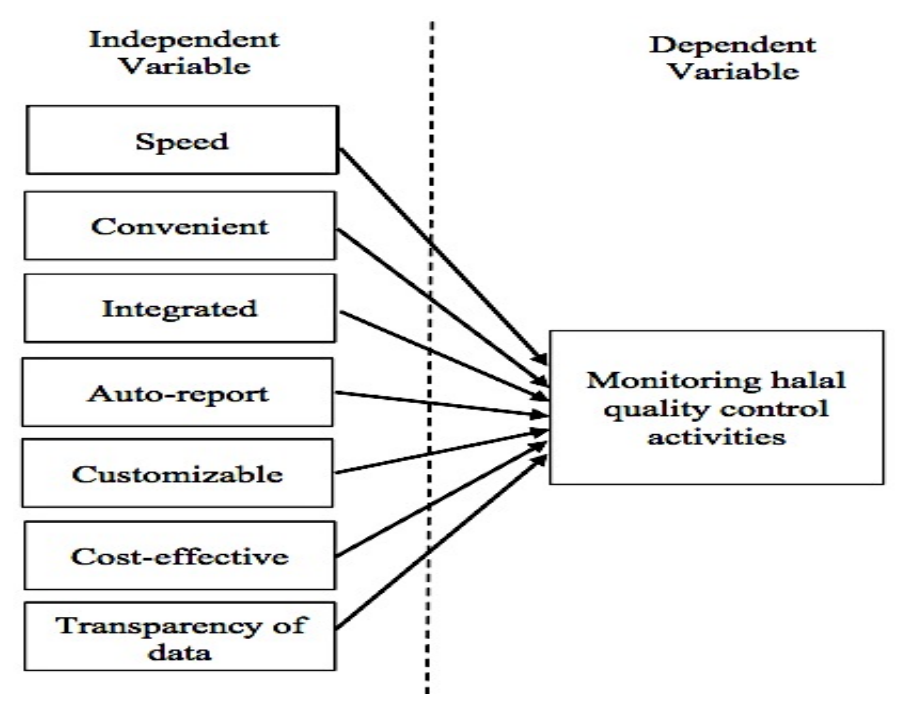

Figure 2. Research Conceptual Framework

\section{Methods}

\section{Survey Distribution and Data Collection}

Malaysian International Halal Showcase (MIHAS) 2016 was chosen as the venue for pilot study as local and international Halal companies in various sizes from micro to multinational, are gathered in one place to showcase their products. The result achieved from the reliability test for a pilot study showed that the questions used in the questionnaire survey are reliable with Cronbach alpha, $\alpha=0.643$. The questionnaire was improved for the use of main data collection. The respondent distribution of each industry segment is as shown in Table 2.

Table 2. Survey Respondent Distribution

\begin{tabular}{llll}
\hline Industry & Sample size & Total Respond & Valid \\
\hline F\&B & 62 & 63 & 46 \\
Consumer & 53 & 36 & 36 \\
Good & & & \\
Cosmetics & 52 & 39 & 39 \\
Logistics & 50 & 50 & 50 \\
\hline Total Company Participated & & 171 \\
\hline
\end{tabular}


The sample size was based on the company's population for each industry segment in Johor Bahru, Malaysia. One hundred seventy-one companies have participated in this survey [15-18]. Four types of halal industry segments: F\&B, consumer goods, cosmetics, and logistics were chosen to represent the highest number of company establishments in Johor. A 5-point Likert scale was used to allow the respondent to express how much they agree or disagree to the statements in the questionnaires. Ranging from strongly disagree to strongly agree. The research design is shown in Figure 3.

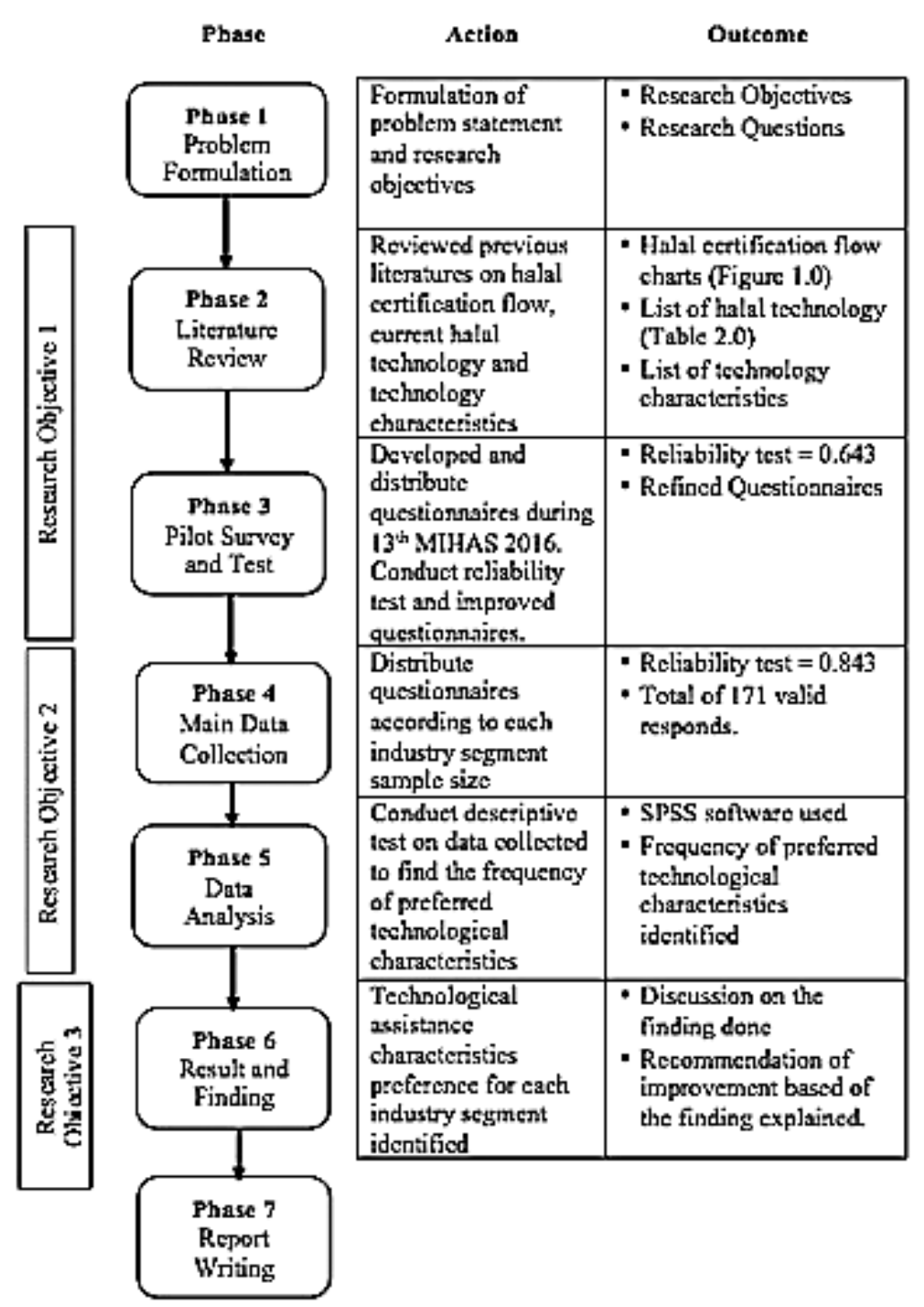

Figure 3. Research Design

The main data collection was done using an online survey. Invitation email to 400 Malaysian Halal certified companies in Johor that consist of $28 \%$ of F\&B, 24.4\% consumer goods, $24 \%$ cosmetics, and 23\% logistics. 176 (43\%) valid responses were received within 30 days. The researcher has performed the reliability test and achieves a better result of $\alpha=0.843$. According to Tabachnick \& Fidell, smaller sample size of 150 - 200 cases should be sufficient to perform analysis if the solution has several loading maker variables above 80 [19]. 


\section{Results and Discussion}

Overall, the findings acquire from data collected show that strongly agree are the highest bar in all charts for all industry segments. This shows that most of the respondents have strong agreement that all characteristics evaluate is important to them in choosing technological solutions. This has clearly shown in Figure 4.

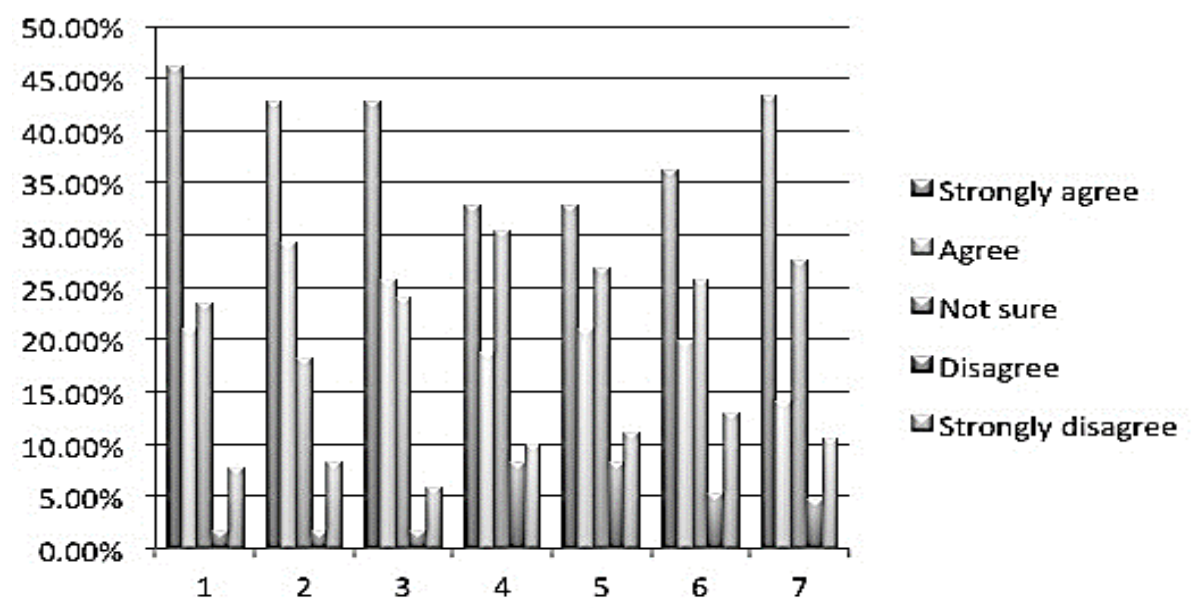

NOTE: 1 = Speed, 2 = Convenient, $3=$ Integrated, $4=$ Auto-report, $5=$ Customizable, $6=$ Cost - effective, 7 = Transparent.

Figure 4. Response Chart

To achieve the second objective of this research, mean tests were conducted for each technology characteristic in each industry segment. Analysis from the mean test shown in Table 3 demonstrated that speed (4.1), convenience (4.0), auto-report capability (3.86) are the most preferred characteristics that the industry had selected to be incorporated in their technology solutions [15-18].

Table 3. Summary of Mean Analysis

\begin{tabular}{ll}
\hline Technology Characteristics & Mean \\
\hline Speed & 4.10 \\
Convenient & 4.00 \\
Auto-Report & 3.86 \\
Transparency of data & 3.76 \\
Cost-Effective & 3.77 \\
Integrated & 3.67 \\
Customizable & 3.58 \\
\hline
\end{tabular}

The highest characteristics demand is at speed at 4.10 followed by convenience at 4.00 . These two characteristics played the most important role to the industry when it comes to having technological support in assisting them to meet JAKIM halal requirements. Other characteristics such as integrated, auto-report generated, customizable, cost-effective, and transparency of data are also important where the mean analysis result showed above 3.5 for all constructs, which these range between unsure (3) to agree (4). 
This research provides a foundation for future empirical studies on technology requirements for halal quality management. This study has delivered major evidence for the contention that all seven characteristics of the study, namely speed, convenience, integrated, auto-report, customizable, cost-effective, and transparency of data, are important and needed by the industry to assist them in applying for halal certification. Gaining halal status for a company is an added value, especially in competing with another halal producer in the global halal market.

The significant contribution of this study is to identify the technology features that industries need to look for in helping them to comply and monitor with Malaysia Halal certification and quality requirements. Technology developers can use these research findings to develop technologies that would really suit the industry's needs. Besides that, another significant contribution of this study is to encourage future research on multifarious dimensions and the contribution of technology design and development specifically for the halal industry, for instance, the application of the $4^{\text {th }}$ Industrial Revolution in halal business operations. Exploratory and explanatory research can be conducted on the application of the internet of things, blockchain, smart logistics, robotics, big data, etc. in halal supply chain processes.

To summarize, this study has succeeded in stipulating evidence to achieve the objectives outlined for this research. Seven important categories of technology characteristics have been identified. All seven of these characteristics are significant where all these categories are needed and perceived as important by all four segments of the industry studied. Speed and convenience are the top two desired characteristics for a technology. This explained that in the current business situation, industries are always looking for the fastest way but convenient to use in doing their work. Cost is not the major issue if they are able to get the job done in the quickest time. This is shown from the finding where cost-effective falls at number five.

This research is limited to only four halal industry segments instead of seven; there were F\&B, consumer goods, cosmetics, and logistics. The industry segment that was not included in this study is pharmaceuticals, slaughtering house, and food premises. This research also only concentrated on Johor-based companies and studied the general characteristics of technology solutions. However, from these limitations comes the opportunity for future studies. A study could be carried out on industries beyond the boundary of Johor state. A comparison analysis can be conducted to see the differences and the common preference of technology characteristics between states in Malaysia. This study can also be extended to the other three industry segments that are pharmaceuticals, slaughtering houses, and food premises. Another good study could also be conducted on looking to a specific technology such as mobile technology, cloud services, and data analytical dashboard. These studies will give a much more concise and specific finding that will benefit both users and the system developers.

\section{Conclusions}

In conclusion, technology that can increase speed and at the same time be convenient and easy to use may be more desired by the industry regardless of the cost. Besides that, understanding the desired characteristics of technology is the necessary enabler of promoting the development of suitable technology to assist the halal industry. Finally, this study has also made a major contribution to future innovation in technology application in the halal industry by providing the characteristics required by the industry in assisting them to be players in the halal marketplace. 


\section{Data Availability}

Readers able to access the data underlying the findings of the study by contacting HOLISTICS Lab Sdn. Bhd.: http://holisticslab.my/ or contact the correspondent author.

\section{Acknowledgments}

The authors would like to thank Universiti Teknologi Malaysia (UTM) for the support in making this project possible. This work was supported by Research Universiti Grant (Q.J130000.2409.04G92) initiated by UTM. The authors also like to express our gratitude to thank Center for Innovative Planning and Development (CIPD), Faculty of Built Environment and Surveying (FBES) and Surveying, Azman Hashim Business School (AHIBS) and Center of Research for Fiqh Science and Technology (CFiRST) of Universiti Teknologi Malaysia for their continuous support in terms of knowledge sharing and providing space and training throughout this study. Last but least to HOLISTISCS Lab Sdn. Bhd. for giving us the opportunity to be part of the halal research team and allowing us to learn so much on halal industry holistically.

\section{References}

[1] Halal Standard (MS1500), "Standard 1500: 2004 - Halal Food: Production, Preparation, Handling and Storage - General Guidelines (1st Revision)." Malaysia Standard, Kuala Lumpur, 2004.

[2] I. R. F. A. N. Sungkar, P. A. Z. I. M. Othman, and W. W. Hussin, "Potentials of global halal food market: Implications for Vietnamese SMEs," 2008.

[3] A. Kagan, "Information technology seen as key to productivity.," Chem. Week, vol. 155, no. 2, pp. 20-22, 1994.

[4] F. W. McFarlane, "Information technology changes the way you compete," Harv. Bus. Rev., vol. 62, no. 3, pp. 98-103, 1984.

[5] G. L. Parsons, "Information technology: a new competitive weapon," Sloan Manag. Rev., vol. 25, no. 1, pp. 3-14, 1983.

[6] F. C. Weston Jr, "Weighing 'soft'and 'hard'benefits of information technology," Manuf. Syst., vol. 11 , no. 7, pp. 120-121, 1993.

[7] JAKIM, "Halal Malaysia," www.halal.gov.my, 2011. .

[8] JAKIM, "Manual Procedure for Malaysia Halal Certification (Third Revision)." Jabatan Kemajuan Islam Malaysia (Jakim), Selangor, Malaysia, 2014.

[9] F. Dewhurst, A. R. M. Lorente, and B. G. Dale, "Total quality management and information technologies: an exploration of the issues," Int. J. Qual. Reliab. Manag., vol. 16, no. 4, pp. 392406, 1999.

[10] S. A. Brah and H. Y. Lim, "The effects of technology and TQM on the performance of logistics companies," Int. J. Phys. Distrib. Logist. Manag., vol. 36, no. 3, pp. 192-209, 2006.

[11] Z. J. M. Husny, M. I. I. Tan, I. S. Ibrahim, and M. Z. A. Rozan, "Assessment on the utilization of current halal certification technologies by halal industry players in Malaysia," in Proceeding of The World Congress on Engineering and Computer Science, 2014, vol. 2, pp. 22-24.

[12] F. D. Davis, "Perceived usefulness, perceived ease of use, and user acceptance of information technology," MIS Q., vol. 13, no. 3, pp. 319-340, 1989.

[13] S. S. Al-Gahtani, "System characteristics, user perceptions and attitudes in the prediction of information technology acceptance: A structural equation model," 1998.

[14] Y. C. Cho and E. Sagynov, "Exploring factors that affect usefulness, ease of use, trust, and purchase intention in the online environment," Int. J. Manag. Inf. Syst., vol. 19, no. 1, pp. 21-36, 2015.

[15] Z. J. M. Husny, M. I. I. Tan, N. Sulong, N. S. Yusof, and M. N. A. Mazlan, "Technology requirement for halal quality control: Logistics," J. Fundam. Appl. Sci., vol. 10, no. 2S, pp. 399412, 2018.

[16] Z. J. M. Husny, M. I. I. Tan, N. Sulong, N. S. Yusof, and M. N. A. Mazlan, "Technology requirement for halal quality control: Cosmetics," J. Fundam. Appl. Sci., vol. 10, no. 2S, pp. 399-412, 2018. 
[17] Z. J. M. Husny, M. I. I. Tan, N. Sulong, N. S. Yusof, and M. N. A. Mazlan, "Technology requirement for halal quality control: Consumer Goods," J. Fundam. Appl. Sci., vol. 10, no. 2S, pp. 399-412, 2018.

[18] Z. J. M. Husny, M. I. I. Tan, N. Sulong, N. S. Yusof, and M. N. A. Mazlan, "Technology requirement for halal quality control: Food and Baverages," J. Fundam. Appl. Sci., vol. 10, no. 2S, pp. 399-412, 2018.

[19] B. G. Tabachnick, L. S. Fidell, and J. B. Ullman, Using multivariate statistics, vol. 5. Boston, MA: Pearson, 2007.

\section{Corresponding author biography}

Zuhra Junaida Mohamad Husny Hamid holds a Ph.D. in Transportation Planning from Faculty of Build Environment the Universiti Teknologi Malaysia, Johor. Her Ph.D. research was entitled "The Determinant Factors Towards the Intention to Adopt Halal Logistics Services". She also holds a Master of Science in Transport Planning from the same university. Her master dissertation entitled "The Needs of Halal Transportation Control in Malaysia". Her degree and diploma in Computer Science were from the School of Computing, Universiti Teknologi Malaysia. She is also a chartered member of Chartered Institute of Logistics and Transport (CILT) UK. She is currently actively involved in Halal Logistics and other research areas related to Halal industries, as this is not only her area of research interest but also one of her areas of training expertise. Her research work on halal logistics started from 2011 until now. She is co-founder for HOLISTICS Lab Sdn Bhd, a spin of company from UTM that provides technology solutions for halal industry. Two main projects for HOLISTICS among others are QuikHalal and Hacademy. 